Family Profile No. 03, 2018

\title{
Prevalence of Grandparenthood in the U.S.
}

Author: Huijing Wu

In 2014, approximately 62 million adults aged 50 and older were grandparents, according to the Survey of Income and Program Participation (SIPP). The SIPP is a nationally representative household-based survey and is designed to provide comprehensive family and social information on individuals and families. Because the SIPP gathers information on all individuals who lived in a surveyed household, and directly asks respondents if they are a grandparent, it is one of the few surveys that identifies nonresident grandparents. In this profile, we identify the prevalence of grandparenthood among adults aged 50 and older and examine their demographic characteristics including race/ethnicity, educational attainment, and current relationship status. This profile, an update of FP-14-14, is the third in our series on grandparents in the U.S.

\section{Overall, $58 \%$ of adults 50 and older in the U.S. are grandparents.}

\section{Race/Ethnicity and Grandparenthood}

- Among adults aged 50 and older, a greater percentage of Blacks and Hispanics were grandparents than those of other racial/ethnic backgrounds in 2014. Roughly, three in five Black and Hispanic adults were grandparents.

- Asian adults had the smallest share who reported being a grandparent (49\%).

Figure 1. Grandparenthood by Race/Ethnicity, 2014

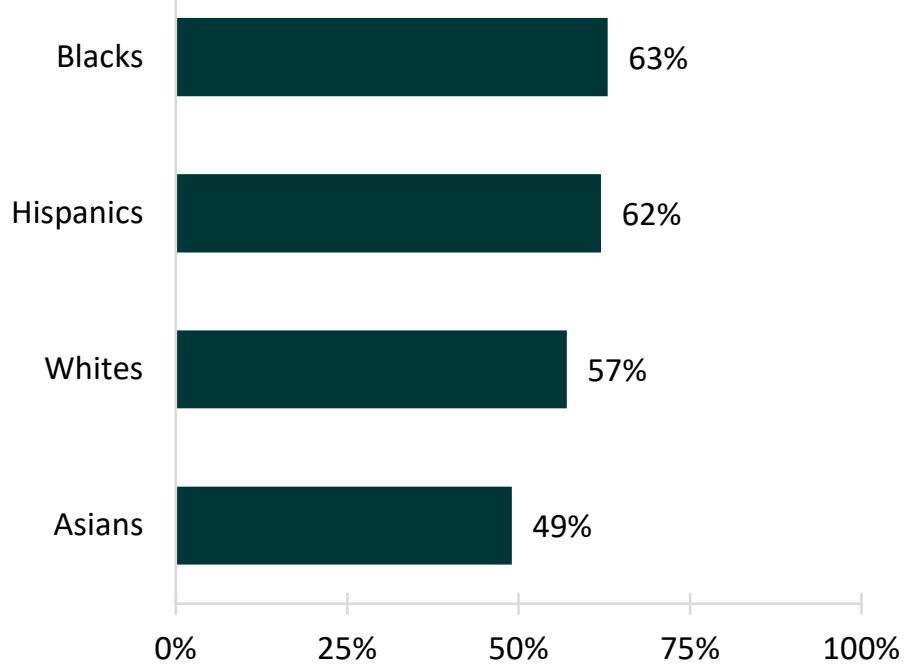

Source: NCFMR analyses of U.S. Census Bureau, Survey of Income and Program Participation, 2014 


\section{Educational Attainment and Grandparenthood}

Figure 2. Grandparenthood by Educational Attainment, 2014

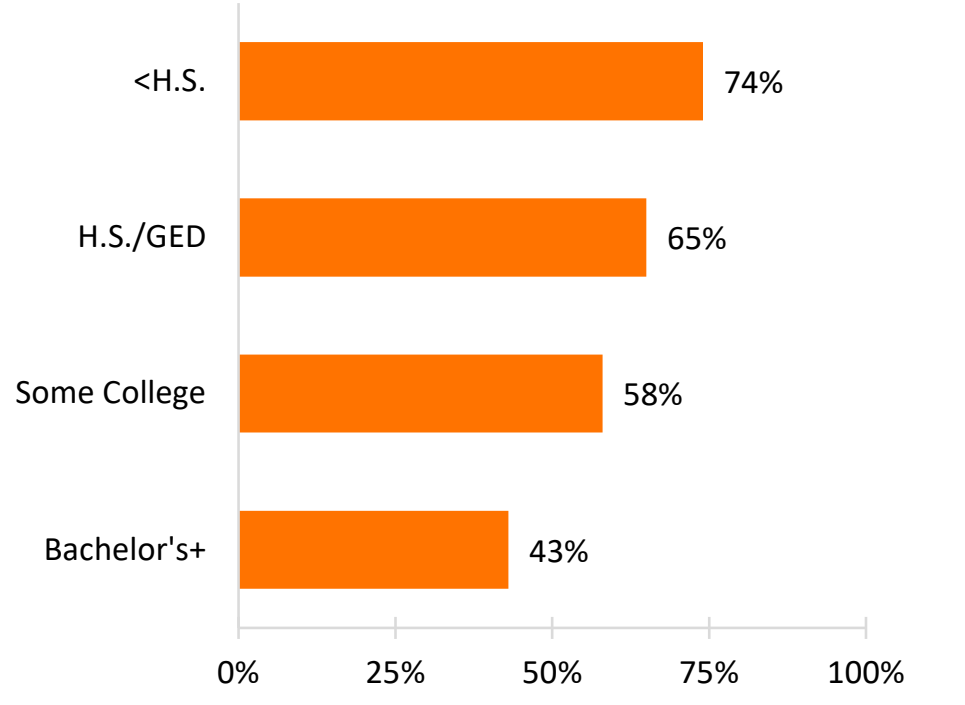

Source: NCFMR analyses of U.S. Census Bureau, Survey of Income and Program Participation, 2014

The prevalence of grandparenthood decrease $d$ as educational attainment increased.

- Among those aged 50 or older in 2014 without a high school diploma/GED, three-fourths were grandparents.

- Being a grandparent was least common among those who had at least a Bachelor's degree (43\%).

\section{Relationship Status and Grandparenthood}

Figure 3. Grandparenthood by Relationship Status, 2014

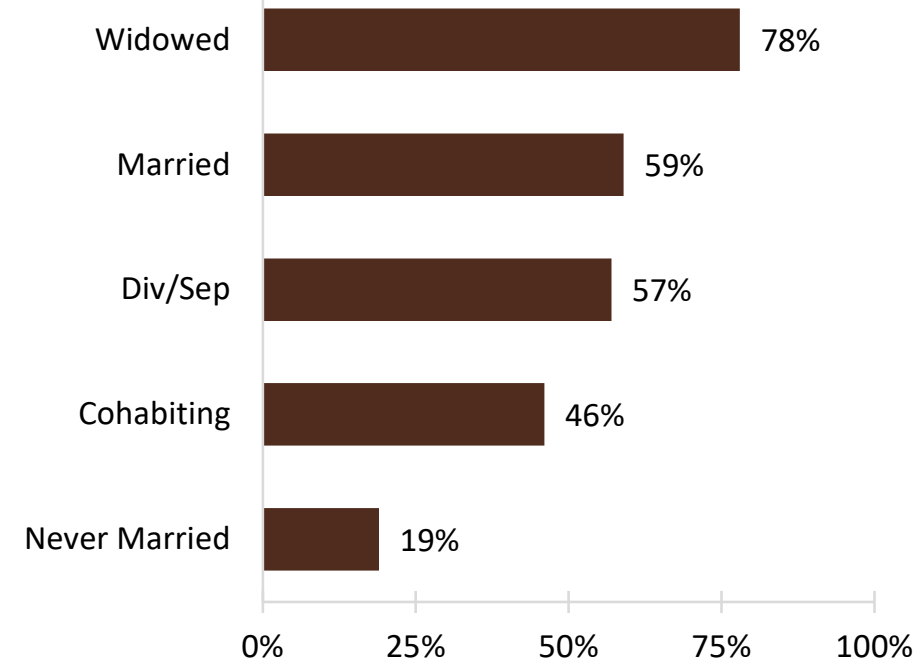

Source: NCFMR analyses of U.S. Census Bureau, Survey of Income and Program Participation, 2014

- Being a grandparent was most common among widowed adults, at $78 \%$. This is not unexpected because the widowed are more often older.

- Similar shares of married and divorced/separated adults were grandparents ( $59 \%$ and $57 \%$, respectively). Slightly less than half (46\%) of cohabiting adults age 50 and older were grandparents.

- Never married adults had the smallest share who reported being a grandparent, at only $19 \%$.

\section{Data Source:}

U.S. Census Bureau, Survey of Income and Program Participation, 2014 Panel, Wave 1. https://www.census.gov/programssurveys/sipp/data/2014-panel/wave-1.html

\section{References:}

Stykes, B., Manning, W. D., \& Brown, S. L. (2014). Grandparenthood in the U.S.: Prevalence of grandparenthood among adults aged 50+. Family Profiles, FP-14-14. Bowling Green, OH: National Center for Family \& Marriage Research.https://www.bgsu.edu/content/dam/BGSU/ college-of-arts-and-sciences/NCFMR/documents/FP/FP-14-14-grandparent-50-plus.pdf

\section{Suggested Citation:}

$\mathrm{Wu}, \mathrm{H}$. (2018). Prevalence of grandparenthood in the U.S. Family Profiles, FP-18-03. Bowling Green, OH: National Center for Family \& Marriage Research. https://doi.org/10.25035/ncfmr/fp-18-03.

B O w L I N G G R E E N S T A t E U N I v E R s I T Y
This project is supported with assistance from Bowling Green State University. From 2007 to 2013, support was also provided by the U.S. Department of Health and Human
Services, Office of the Assistant Secretary for Planning and Evaluation. The opinions and conclusions expressed herein are solely those of the author(s) and should not be construed
as representing the opinions or policy of any agency of the state or federal government.

